\title{
Taking advantage of mobile devices: Using Socrative in the classroom
}

\author{
Pamela D. Wash ${ }^{1}$ \\ Keywords: mobile technology, BYOD, instructional technology
}

Framework

"If we teach today as we taught yesterday, we rob our children of tomorrow", (Dewey, 1916). In higher education, "we have the opportunity to teach students to ask the right questions, use the real-world tools that they have in their hands to find the best answers, and share that in an authentic way with those around them" (Nelson, 2012). In 2012, EDUCAUSE, a leader in IT advancement for higher education, published its findings of a survey disseminated to 195 participating institutions receiving more than 100,000 student responses. According to this report, ECAR Study of Undergraduate Students and Information Technology Report (Dahlstrom, 2012), students prefer blended and flipped classrooms, they yearn for seamless integration of mobile technology, they believe technology is critical for both academic success and career accomplishments, and they value multiple options for communicating. Additionally, these results report that $86 \%$ own a laptop, $62 \%$ own a smartphone, $33 \%$ own a desktop computer, $15 \%$ own a tablet, and $12 \%$ own an e-reader.

The data are clear; the data cannot be ignored. Students are demanding seamless integration of the varied technologies and mobile devices they own and command. In having valid confirmation from a national perspective, institutions of higher education are faced with the challenge of how to respond. These digital natives are demanding that institutions of learning catch up with the $21^{\text {st }}$ century and engage them using the technologies that are a daily staple of their lives. Long gone are the days of standard lecture and PowerPoint presentations from higher education faculty (Wash \& Freeman, 2013).

This article describes how one faculty member engages students in the classroom using their own devices, regardless of platform, with the interactive, real-time, web-based student response system tool, Socrative (2013).

\section{Making it Work}

Student response systems or clickers are not new to the classroom. There are numerous brands and manufacturers available; however, each requires an additional purchase by either the faculty member or individual student. Now, there are free web 2.0 tools that provide instructors the flexibility and spontaneity of both formal and informal engagement in the classroom using the varied mobile devices students bring to the classroom.

After conducting online research of available free web-based student response system tools and in classroom trial and error of several, Socrative appears to offer the most flexibility and ease of use. Additionally, student survey data $(\mathrm{N}=40)$, conducted with two science education methods classes, indicates that using such tools in the classroom increases classroom

\footnotetext{
${ }^{1}$ Associate Professor, College of Education, Winthrop University, pwash@uscupstate.edu
} 
participation, helps provide instant feedback on what students know, and increases mental engagement in class.

\section{Classroom Implementation}

To get started using Socrative, the instructor creates a "teacher account" and assigns a room number. The room number becomes the login key for students to access course material through any web browser on any Internet-accessible device or by installing the "student login app". From the teacher login portal, instructors can create multiple choice, true/false, and short answer assessments or surveys. Additionally, there are options to run a "quick quiz" that is self-paced, and an "exit ticket" to receive feedback from students prior to leaving a class session, or even a team response competitive game feature. Socrative also allows for spontaneous polling by simply clicking the "single question" feature and selecting the question format from multiple choice, true/false, and short response.

In science methods courses for education majors, Socrative allows practice questions for required certification examinations to be provided, pulse checks on critical thinking questions allowing students to respond with anonymity, formal assessment checkpoints, and review of content material opportunities. Each of these options provides both the instructor and the students with real-time feedback, jumpstarts classroom discourse, and encourages active participation.

When surveys or assessments are engaged, students simply access the Socrative website using a laptop, Smartphone, or tablet, click on the Student Log In portal, and type in the room number provided by the instructor. When the survey or assessment begins, the instructor can elect to display live results as they are submitted or hide the results until all responses are received. All data collected for each assessment are stored and archived within Socrative and can easily be retrieved and exported in an Excel spreadsheet for formal documentation.

\section{Table 1}

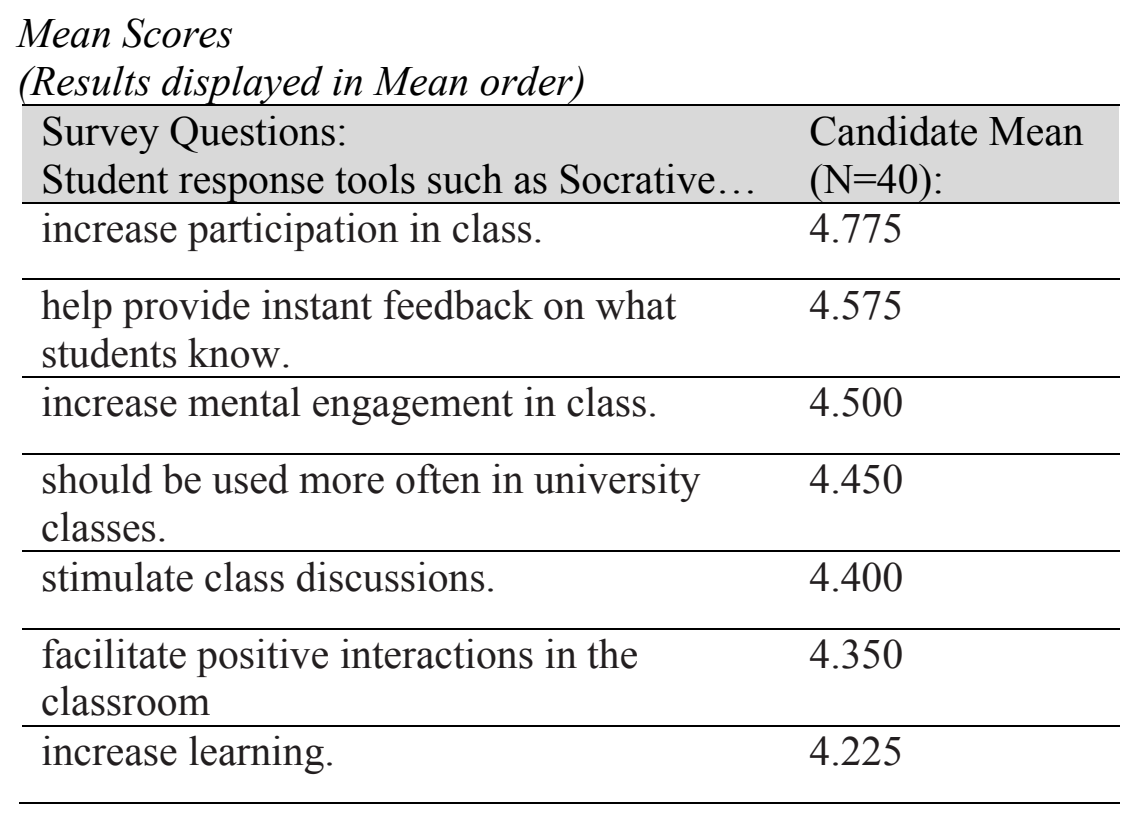


Feedback from students on semesterly administered student opinion poll evaluations indicates positive attitudes toward the use of this technology and form of engagement in the classroom. A few student comments include, "I feel comfortable responding to content questions using the clickers rather than responding out loud" to "I appreciate the instructor including Praxis II practice questions in class. This helps ease my anxiety as I prepare for these exams".

In addition to the semesterly administered student opinion poll evaluations, a survey developed by the instructor/researcher was administered in two science education methods courses $(\mathrm{N}=40)$ to formalize students' responses to using Socrative daily in the classroom. The survey instrument consisted of seven Likert-scale questions with indicators from strongly agree (value: 5) to strongly disagree (value: 1). The aggregate mean results (see Table 1) indicate that students strongly believe response technology increases participation in class (4.78), that this technology helps to provide instant feedback on what students know (4.58), and increases mental engagement in class (4.50). In contrast, student survey results yielded slightly lower responses for whether or not student response tools such as Socrative facilitated positive interactions in the classroom (4.35) and increased learning (4.23).

\section{Future Implications}

As society becomes even more heavily dependent on mobile technology, it is imperative that our classrooms begin to embrace and take advantage of this instructional medium. Rather than viewing this technology as a "disruptive innovation", a phrase coined by Harvard Business School professor Clayton Christensen, faculty can find innovative ways to engage their students using the varied instructional technology devices they bring to the learning environment.

\section{References}

Dahlstrom, E. (2012). ECAR Study of undergraduate students and information technology, 2012 (Research Report). Louisville, CO: EDUCAUSE Center for Applied Research.

Dewey, J. (1916). Democracy and education: An introduction to the philosophy of education. NY: Freepress.

Nelson, D. (2012). BYOD. Internet@Schools,19(5),12-15.

Socrative. (2013). Socrative. [Mobile application software]. Retrieved from http://socrative.com/.

Wash, P.D. \& Freeman, G. G. (2013). BYOD - Engaging Students Using Their Own Devices. National Social Science Technology Journal, 3(1). 